\title{
Proposal of Mingxiaea gen. nov. for the anamorphic basidiomycetous yeast species in the Bulleribasidium clade (Tremellales) based on molecular phylogenetic analysis, with six new combinations and four novel species
}

\author{
Qi-Ming Wang, ${ }^{1}$ Feng-Yan Bai, ${ }^{1}$ Bundit Fungsin, ${ }^{2}$ Teun Boekhout ${ }^{3}$ \\ and Takashi Nakase ${ }^{4}$
}

Correspondence

Feng-Yan Bai

baify@im.ac.cn

\author{
${ }^{1}$ Key Laboratory of Systematic Mycology and Lichenology, Institute of Microbiology, Chinese \\ Academy of Sciences, Beijing 100101, PR China \\ ${ }^{2}$ Thailand Institute of Scientific and Technological Research (TISTR), Klong Luang, Pathumthani \\ 12120, Thailand \\ ${ }^{3}$ Centraalbureau voor Schimmelcultures, Yeast Division, Uppsalalaan 8, 3584 CT Utrecht, The \\ Netherlands \\ ${ }^{4}$ Biological Resource Center (NBRC), Department of Biotechnology, National Institute of \\ Technology and Evaluation, Kisarazu, Chiba 292-0818, Japan
}

\section{INTRODUCTION}

Bullera variabilis was described by Nakase \& Suzuki (1987) to accommodate a group of yeast strains forming variously shaped ballistoconidia. Bai et al. (2001) redefined the concept of Bullera variabilis and reclassified the strains

Abbreviation: ITS, internal transcribed spacer.

The GenBank/EMBL/DDBJ accession numbers for the 18S rRNA gene, ITS region and 26S rRNA gene D1/D2 domain sequences determined in this study are GQ438828-GQ.438843 and GU327539GU327541.

Additional phylogenetic trees are available with the online version of this paper. previously assigned to this species based on $18 \mathrm{~S}$ rRNA gene and internal transcribed spacer (ITS) region sequencing and DNA-DNA reassociation. The strains represented five species, four of which belong to the recently proposed genus Derxomyces (Bai et al., 2001; Wang \& Bai, 2008). Molecular phylogenetic analysis of the genus Cryptococcus and related tremellomycetous yeast species based on $18 \mathrm{~S}$ rRNA gene sequencing showed that Bullera variabilis was not closely related to the Bulleromyces lineage containing the type species of the genus Bullera, but was located in a separate branch basal to the Hannaella luteola (formerly Cryptococcus luteolus) lineage with only moderate bootstrap support in the phylogenetic tree drawn from maximumparsimony analysis (Takashima \& Nakase, 1999). The 
distinction of the Bullera variabilis branch was also shown in a neighbour-joining tree, but its position was not definitely resolved (Takashima \& Nakase, 1999). Extensive molecular taxonomic studies on basidiomycetous yeast species based on sequence analyses of the D1/D2 variable domains of the large subunit (26S) rRNA gene and ITS region also indicated that Bullera variabilis was located in a separate branch that was only distantly related to the Bulleromyces clade which contains the type species of the genus Bullera (Fell et al., 2000; Scorzetti et al., 2002).

Boekhout et al. (1991) observed mating and dikaryotic hyphae with clamp connections between two Bullera variabilis strains; however, they did not observe basidial development. A teleomorphic species, Bulleribasidium oberjochense, closely related to Bullera variabilis was described by Sampaio et al. (2002). The basidium structure and morphology of Bulleribasidium oberjochense differ markedly from those of Bulleromyces albus (Boekhout et al., 1991). The latter is the teleomorph of Bullera alba, which is the type species of the genus Bullera. Unlike Bulleromyces albus, which forms typically longitudinally to obliquely septate and globose basidia, Bulleribasidium oberjochense normally forms transversally septate and cylindrical basidia (Sampaio et al., 2002). The differences in sexual stages support the distinction of the anamorphic species in the Bulleribasidium clade from the Bullera species in the Bulleromyces clade at the generic level.

The polyphyletic nature of the genus Bullera and related genera as defined on the basis of only phenotypical criteria (Boekhout \& Nakase, 1998) has long been recognized. The requirement for revising the genus has been emphasized by the continued discovery of many new Bullera species in recent years, which has contributed to the increase in the polyphyletic nature of the genus. The distribution of species of the genus Bullera has expanded from the orders Tremellales and Filobasidiales to the order Trichosporonales (Nakase et al., 2002; Fungsin et al., 2006). Reclassification of the genus Bullera and related genera of basidiomycetous yeasts has been under way and two new genera, Derxomyces and Hannaella, have been proposed for the species of the genus Bullera in two distinct clades of the Hannaella luteola lineage in the order Tremellales (Wang \& Bai, 2008).

In recent years, five novel anamorphic species closely related to Bulleribasidium oberjochense have been described from different countries in Asia (Bai et al., 2003; Fungsin et al., 2003; Nakase et al., 2004), expanding the branch to a distinct clade. These studies also suggest that species of the Bulleribasidium clade are commonly distributed in natural sources. In a recent survey of ballistoconidium-forming yeasts associated with plant leaves in Hainan province, southern China, four novel anamorphic species represented by 16 strains were revealed to belong to the Bulleribasidium clade by rRNA gene sequence analysis. The result confirmed and strengthened the distinction of the Bulleribasidium clade. In order to avoid any further increase in the polyphyletic nature of the genus Bullera, we propose a new genus, Mingxiaea, to accommodate the anamorphic species of the Bulleribasidium clade. Four novel species in the new genus, isolated from plant leaves, are described.

\section{METHODS}

Yeast strains and phenotypic characterization. The strains studied are listed in Table 1. They were isolated from wilting plant leaves using the improved ballistoconidia-fall method as described by Nakase \& Takashima (1993). Morphological, physiological and biochemical characteristics were examined in liquid media according to standard methods (Yarrow, 1998). Assimilation of nitrogen compounds was investigated on solid media with starved inocula (Nakase \& Suzuki, 1987). Extraction, purification and identification of ubiquinones were carried out according to Yamada \& Kondo (1973).

Sequencing and molecular phylogenetic analysis. $18 \mathrm{~S}$ rRNA gene sequences were determined according to Wang et al. (2003). The ITS (including 5.8S rRNA gene) and 26S rRNA gene D1/D2 domain sequences were determined using the methods described by Bai et al. (2002). Sequences were aligned by using the CLUSTAL $x$ program (Thompson et al., 1997). Phylogenetic trees were reconstructed from the evolutionary distance data calculated from Kimura's twoparameter model (Kimura, 1980) by using the neighbour-joining method (Saitou \& Nei, 1987). Bootstrap analyses (Felsenstein, 1985) were performed from 1000 random resamplings. Maximum-parsimony analysis was performed using MEGA version 4 (Tamura et al., 2007) and the heuristic search (close-neighbour-interchange) was used.

\section{RESULTS AND DISCUSSION}

\section{Proposal of Mingxiaea gen. nov.}

In the phylogenetic tree reconstructed from the concatenated ITS and D1/D2 sequences of almost all yeast species in the order Tremellales recognized at the time of writing, the Bulleribasidium clade was clearly resolved with $100 \%$ bootstrap support (Supplementary Fig. S1, available in IJSEM Online). However, the affinity of this clade to the order Tremellales and its relationships to other tremellomycetous clades or species were not confidently shown. Bullera miyagiana was clustered together with Bullera variabilis in a strongly supported branch by D1/D2 sequence analyses (Scorzetti et al., 2002; Sampaio et al., 2002), whereas this affinity was not shown in the ITS tree (Scorzetti et al., 2002).

In order to get a clearer phylogenetic circumscription of the Bulleribasidium clade, a phylogenetic tree based on the alignment of concatenated rRNA gene sequences, including 18S, ITS, 5.8S and 26S D1/D2 domain, was reconstructed using neighbour-joining analysis (Fig. 1). The sequences were from the type strains of $i$ ) all the described species and proposed novel species in the Bulleribasidium clade; ii) representative species of the other genera or clades in the order Tremellales; and iii) representative species of the other orders or lineages of tremellomycetous yeasts. The 
Table 1. Yeast strains studied

\begin{tabular}{|c|c|c|c|}
\hline Species & Strain & Other designation & Source \\
\hline \multirow[t]{3}{*}{ Mingxiaea sanyaensis } & SY $-3.23^{\mathrm{T}}$ & AS $2.3623^{\mathrm{T}}$, CBS $11408^{\mathrm{T}}$ & Leaf of a plant, Sanya, Hainan, China \\
\hline & SY-3.39 & AS 2.3450 & Leaf of a plant, Sanya, Hainan, China \\
\hline & JF-12.9 & AS 2.3519 & Leaf of a plant, Jianfa Mountain, Hainan, China \\
\hline \multirow[t]{2}{*}{ Mingxiaea hainanensis } & WZS- $8.13^{\mathrm{T}}$ & AS $2.4161^{\mathrm{T}}$, CBS $11409^{\mathrm{T}}$ & Leaf of Panicum brevifolium, Wuzhi Mountain, Hainan, China \\
\hline & JF-4.5 & AS 2.2 .4026 & Leaf of a plant, Jianfa Mountain, Hainan, China \\
\hline \multirow[t]{10}{*}{ Mingxiaea foliicola } & WZS-7.24 & & Leaf of a plant, Wuzhi Mountain, Hainan, China \\
\hline & WZS-8.14 ${ }^{\mathrm{T}}$ & AS $2.3518^{\mathrm{T}}$, CBS $11407^{\mathrm{T}}$ & Leaf of Panicum brevifolium, Wuzhi Mountain, Hainan, China \\
\hline & WZS-17.3 & AS 2.4023 & Leaf of Melastoma candidum, Wuzhi Mountain, Hainan, China \\
\hline & WZS-22.20 & AS 2.4019 & Leaf of a Rubiaceae plant, Wuzhi Mountain, Hainan, China \\
\hline & WZS-30.19 & AS 2.4021 & Leaf of a plant, Wuzhi Mountain, Hainan, China \\
\hline & WZS-36.6 & AS 2.3520 & Leaf of a plant, Wuzhi Mountain, Hainan, China \\
\hline & HBX-1.21 & AS 2.4017 & Leaf of a plant, Bangxi, Hainan, China \\
\hline & HBX-2.10 & & Leaf of a plant, Bangxi, Hainan, China \\
\hline & HBX-2.19 & AS 2.4025 & Leaf of a plant, Bangxi, Hainan, China \\
\hline & JF-12.4 & AS 2.3524 & Leaf of a Orchidaceae plant, Jianfa Mountain, Hainan, China \\
\hline Mingxiaea wuzhishanensis & WZS-29.8 ${ }^{\mathrm{T}}$ & AS $2.4163^{\mathrm{T}}$, CBS $11411^{\mathrm{T}}$ & Leaf of a plant, Wuzhi Mountain, Hainan, China \\
\hline
\end{tabular}

distinction of the Bulleribasidium clade was confirmed in the tree with $100 \%$ bootstrap support. The close affinity of this clade to the Hannaella luteola lineage was resolved with $94 \%$ bootstrap support. The affinity of Bullera miyagiana to the Bulleribasidium clade was not supported. This species was located in another branch (Fig. 1). The Bulleribasidium clade was also clearly resolved by maximum-parsimony analysis from the concatenated rRNA gene sequence alignment. The bootstrap support for the close relationship of this clade to the Hannaella luteola lineage was $78 \%$ (Supplementary Fig. S2).

In the Hannaella luteola lineage, the three clades Derxomyces, Hannaella and Dioszegia are closely related. Therefore, in addition to the nuclear rRNA gene sequences, mitochondrial cytochrome $b$ gene sequence and morphological differences were employed to support the separation of the three clades at the generic level (Wang \& Bai, 2008). However, in the case of the Bulleribasidium clade, its distinction from the other clades or lineages in the order Tremellales is more evident, as shown in Fig. 1 and Supplementary Figs S2 and S3, even though only nuclear rRNA genes were employed. We think it is not necessary to add more genes. Phenotypically, the species in the Bulleribasidium clade usually form whitish to yellowish colonies with a butyrous to matted texture, differing from those of the species of the genus Bullera in the Bulleromyces clade which usually form whitish colonies with a highly mucoid texture running to the bottom of the slant. The colonies of yeasts in the Bulleribasidium clade are similar to those of species of the genus Derxomyces, but differ from those of species of the genus Dioszegia which are usually orange in colour and from those of species of the genus Hannaella which are usually mucoid in texture (Wang \& Bai, 2008).

Except for the single teleomorphic species Bulleribasidium oberjochense, sexual stages have not been found in the other described species of the clade. DNA-DNA reassociation experiments indicated that Bulleribasidium oberjochense does not represent the sexual stage of Bullera variabilis, though they are closely related (Sampaio et al., 2002). The occurrence of mating among strains of Bullera variabilis reported by Boekhout et al. (1991) was not observed by Sampaio et al. (2002). In our own mating experiments among newly isolated yeast strains belonging to described and undescribed species of the clade, we also failed to observe sexual cycles. Therefore, a new genus, Mingxiaea gen. nov., is proposed to accommodate the anamorphic species of the Bulleribasidium clade.

\section{Latin diagnosis of Mingxiaea F.-Y. Bai, Q.-M. Wang, T. Boekhout \& Nakase gen. nov.}

Cellulae vegetativae ovoideae, ellipsoideae, elongatae vel ampulliformes. Ballistoconidia flabelliformia, ellipsoideae, napiformia vel turbinatae. Cultura cremea aut gilvo-flavae, butyracea, non nitida vel nitida, glabra vel rugosa, margine glabra. Mycelium aut pseudomycelium formantur. Fermentatio nulla. Urea finditur. Diazonium caeruleum B positivum. Ubiquinonum majus: Q-10. Species typica: Mingxiaea variabilis (Nakase \& Suzuki) F.-Y. Bai, Q.-M. Wang \& Nakase comb. nov.

\section{Description of Mingxiaea F.-Y. Bai, Q.-M. Wang, T. Boekhout \& Nakase gen. nov.}

Mingxiaea (Ming.xia' e.a. N.L. fem. n. Mingxiaea named in honour of Mingxia Li, formerly professor at the Institute of Microbiology, Chinese Academy of Sciences, for her pioneering contributions to the taxonomy of ballistoconidium-forming yeasts in China).

Budding cells are ovoid, ellipsoidal, elongate or bottle-shaped and occur singly or in pairs. Ballistoconidia are flabelliform, ellipsoidal, napiform and turbinate. Colonies are cream to pinkish-yellowish-brown, butyrous, dull or shiny, smooth or 


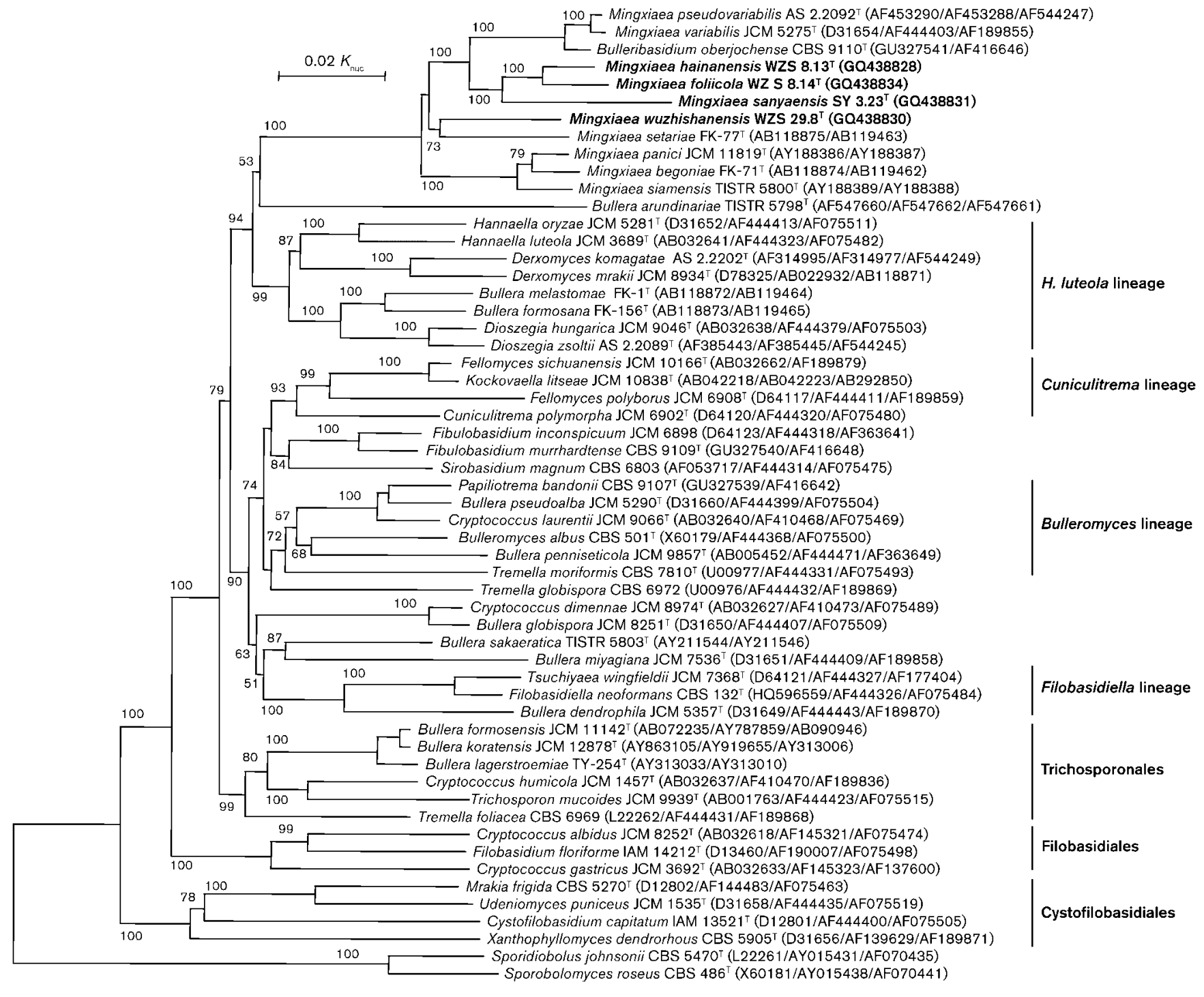

Fig. 1. Phylogenetic tree reconstructed from neighbour-joining analysis of the combined sequences of the 18S rRNA gene, ITS region (including 5.8S rRNA gene) and 26S rRNA gene D1/D2 domain, depicting the relationships of the clades or lineages in the Tremellomycetes. All positions containing gaps were eliminated and there were a total of 2322 positions in the final dataset. Bootstrap percentages over $50 \%$ from 1000 bootstrap replicates are shown. Sequences are from type strains of the species compared, either determined in this study (in bold) or retrieved from GenBank under the accession numbers indicated. Bar, 0.02 substitutions per nucleotide position.

wrinkled and with an entire margin. Hyphae or pseudohyphae may be present. Clamp connections are absent. Basidia and basidiospores are not formed. Fermentation is absent. Diazonium blue $\mathrm{B}$ and urease reactions are positive. The major ubiquinone is Q-10. This genus is phylogenetically well separated from other genera or clades of the order Tremellales by nuclear rRNA gene sequence analysis (Fig. 1). The type species is Mingxiaea variabilis (Nakase \& Suzuki) Q.-M. Wang, F.-Y. Bai, T. Boekhout \& Nakase comb. nov. The following species are accepted in the genus.

Mingxiaea begoniae (Nakase, Tsuzuki, F. L. Lee \& M. Takashima) Q.-M. Wang, F.-Y. Bai, T. Boekhout \& Nakase comb. nov. Basionym: Bullera begoniae Nakase, Tsuzuki, F. L. Lee \& M. Takashima. Mycoscience 45, (2004), 290.

Mingxiaea panici (Fungsin, Takashima \& Nakase) Q.-M. Wang, F.-Y. Bai, T. Boekhout \& Nakase comb. nov. Basionym: Bullera panici Fungsin, Takashima \& Nakase. Microbiol Cult Coll 19, (2003), 27.

Mingxiaea setariae (Nakase, Tsuzuki, F. L. Lee \& M. Takashima) Q.-M. Wang, F.-Y. Bai, T. Boekhout \& Nakase comb. nov. Basionym: Bullera setariae Nakase, Tsuzuki, F. L. Lee \& M. Takashima. Mycoscience 45, (2004), 292. 
Mingxiaea siamensis (Fungsin, Takashima \& Nakase) Q.-M. Wang, F.-Y. Bai, T. Boekhout \& Nakase comb. nov. Basionym: Bullera siamensis Fungsin, Takashima \& Nakase. Microbiol Cult Coll 19, (2003), 27.

Mingxiaea pseudovariabilis (Bai, Takashima \& Nakase) Q.-M. Wang, F.-Y. Bai, T. Boekhout \& Nakase comb. nov. Basionym: Bullera pseudovariabilis Bai, Takashima \& Nakase. Antonie van Leeuwenhoek 83, (2003), 259.

Mingxiaea variabilis (Nakase \& Suzuki) Q.-M. Wang, F.-Y. Bai, T. Boekhout \& Nakase comb. nov. Basionym: Bullera variabilis Nakase \& Suzuki. J Gen Appl Microbiol 33, (1987) 350.

\section{New species recognition}

Among the symmetrical ballistoconidium-forming yeast strains isolated from plant leaves collected from Hainan province, southern China, 16 strains were found to belong to previously undescribed species in the genus Mingxiaea by D1/D2 and ITS sequence analyses. These strains were classified into four groups represented by strains SY $-3.23^{\mathrm{T}}$ (three strains), WZS-8.13 ${ }^{\mathrm{T}}$ (two strains), WZS-8.14 ${ }^{\mathrm{T}}(10$ strains) and WZS $-29.8^{\mathrm{T}}$ (single strain), respectively (Table 1). The strains within each of the former three groups possessed identical D1/D2 sequences and identical or similar ITS sequences (0-4 mismatches), suggesting that the strains in each of these groups are conspecific.

In the tree drawn from D1/D2 sequences, groups SY-3.23 and WZS-29.8 ${ }^{\mathrm{T}}$ formed two well isolated branches in the Mingxiaea clade (Fig. 2). Each of the two representative strains differed from the described and undescribed species in this clade by $44-51$ mismatches (7-8\%) in the D1/D2 domain and more than $15 \%$ mismatches in the ITS region. The data clearly indicate that the two groups represent two distinct species. Strain ST-186 from Thailand was clustered in the SY $-3.23^{\mathrm{T}}$ group. This Thai strain differed from the Chinese strains by only one substitution in the D1/D2 domain, thus suggesting conspecificity with the latter.

Groups WZS-8.13 ${ }^{\mathrm{T}}$ and WZS-8.14 ${ }^{\mathrm{T}}$ were located in a cluster together with seven strains from Thailand. Three branches were recognized in this cluster: group WZS- $8.13^{\mathrm{T}}$ formed a branch basal to the branch formed by the Thai strain TY-248 and another branch formed by the Chinese strains in group WZS-8.14 ${ }^{\mathrm{T}}$ and six Thai strains (Fig. 2). The representative strains WZS-8.13 ${ }^{\mathrm{T}}$, WZS-8.14 ${ }^{\mathrm{T}}$ and TY-248 of these three branches differed from each other by 14-19 mismatches in the D1/D2 domain and more than 60 mismatches in the ITS region, indicating that they represent three different species. In the branch represented by strain WZS- $8.14^{\mathrm{T}}$, the Thai strains differed from the Chinese strains by 0-4 mismatches in the D1/D2 domain. However, strains TY-154, TY-199 and TY-297, whose ITS sequences were available from GenBank, differed from the Chinese strains in the same branch by $11-$ 12 mismatches in the ITS region, suggesting that the taxonomic status of these Thai strains remains to be confirmed. Another undescribed strain from Thailand,
ST-144, was located in a branch closely related to Bulleribasidium oberjochense, M. variabilis and M. pseudovariabilis. It differed from the three described species by $42-$ 44 mismatches in the D1/D2 domain, suggesting that strain ST-144 belongs to a separate species.

The rRNA gene sequence comparison showed that at least six novel species belonging to the Mingxiaea clade exist among the 16 strains isolated from Hainan, China, and the nine undescribed strains from Thailand whose rRNA gene sequences have been publicly released. Since the Thai strains have not been fully characterized phenotypically, only the four novel species represented by the Chinese strains are named and described below. Sexual cycles were not observed in the single or mixed cultures of the new strains growing on various media. Therefore, four new anamorphic species, Mingxiaea sanyaensis sp. nov., Mingxiaea hainanensis sp. nov., Mingxiaea foliicola sp. nov. and Mingxiaea wuzhishanensis sp. nov. are proposed. The physiological differences of the novel species from each other and from the described species of the genus Mingxiaea are summarized in Table 2.

\section{Latin diagnosis of Mingxiaea sanyaensis Q.-M. Wang, F.-Y. Bai, T. Boekhout \& Nakase sp. nov.}

In YM (Difco) liquido post dies 7 ad $17{ }^{\circ} \mathrm{C}$, cellulae vegetativae ellipsoideae vel ovoideae, $2.5-4.5 \times 5.0-7.2 \mu \mathrm{m}$. Annulus et sedimentum formantur. In agaro YM post unum mensem ad $17{ }^{\circ} \mathrm{C}$, cultura cremea aut flavae, nitida, glabra, butyracea, margine glabra. Mycelium non formantur. Ballistoconidia ellipsoideae, 3.7-5.0 × 5.5-7.5- $\mu \mathrm{m}$. Fermentatio nulla. Glucosum, galactosum, saccharosum, maltosum, cellobiosum, trehalosum, melibiosum, raffinosum, melezitosum, amylum solubile, D-xylosum, L-arabinosum, D-arabinosum, D-ribosum (vel lente), L-rhamnosum, D-glucosaminum (lente et exigue), galactitolum (vel lente et exigue), D-mannitolum (vel lente), glucitolum (vel lente), methyl $\alpha$-D-glucosidum, salicinum (vel exigue) et inositolum assimilantur at non L-sorbosum, lactosum, inulin, methanolum, ethanolum, glycerolum, erythritolum, ribitolum (vel lente et exigue), acidum DL-lacticum, acidum succinicum, acidum citricum nec hexadecanum. Ammonium sulfatum et $\mathrm{L}$-lysinum assimilantur at non kalium nitricum, natrum nitrosum, ethylaminum et cadaverinum. Ad crescentiam vitaminum non necessarium est. Maxima temperatura crescentiae: $30{ }^{\circ} \mathrm{C}$. Materia amyloidea iodophila non formantur. Urea finditur. Diazonium caeruleum B positivum. Ubiquinonum majus: Q-10. Typus: SY-3.23 ${ }^{\mathrm{T}}$, ex folio plantae incognitae, depositus in collectione China General Microbiological Culture Collection Center, Academia Sinica (AS $\left.2.3623^{\mathrm{T}}\right)$.

\section{Description of Mingxiaea sanyaensis Q.-M. Wang, F.-Y. Bai, T. Boekhout \& Nakase sp. nov.}

Mingxiaea sanyaensis (san.ya.en'sis. N.L. fem. adj. sanyaensis pertaining to Sanya, China, the geographical origin of the type strain of this species). 


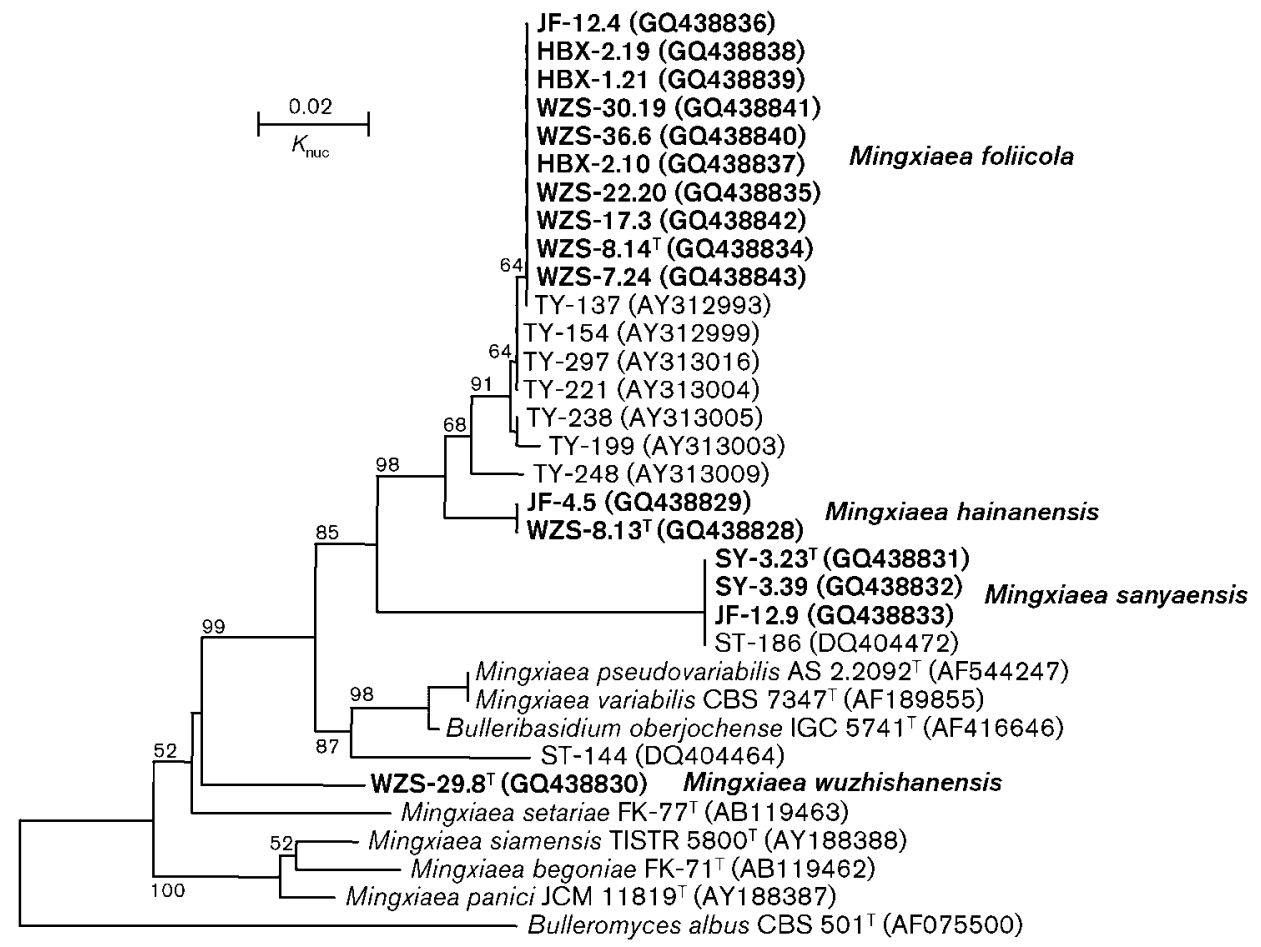

Fig. 2. Phylogenetic tree reconstructed from neighbour-joining analysis of the $26 \mathrm{~S}$ rRNA gene D1/D2 domain sequences depicting the relationships of the novel species of the genus Mingxiaea gen. nov. with closely related taxa. Bootstrap percentages over $50 \%$ from 1000 bootstrap replicates are shown. Sequences are from type strains of the species compared, either determined in this study (in bold) or retrieved from GenBank under the accession numbers indicated. Bar, 0.02 substitutions per nucleotide position.

In YM broth, after 7 days at $17{ }^{\circ} \mathrm{C}$, cells are ellipsoidal or ovoid $(2.5-4.5 \times 5.0-7.2 \mu \mathrm{m})$ (Fig. 3a). Sediment is formed. On YM agar, after 1 month at $17{ }^{\circ} \mathrm{C}$, the streak culture is cream to yellow, butyrous, shiny and smooth. The margin is entire. In Dalmau plate culture on corn meal agar, pseudohyphae and hyphae are not formed. Ballistoconidia are produced on corn meal agar and are ellipsoidal $(3.7-5.0 \times 5.5-7.5 \mu \mathrm{m})$ (Fig. 3b). Fermentation of glucose is negative. Glucose, galactose, sucrose, maltose, cellobiose, trehalose, melibiose, raffinose, melezitose, soluble starch, D-xylose, L-arabinose, D-arabinose, D-ribose (or delayed), L-rhamnose, D-glucosamine (delayed and weak), galactitol (or delayed and weak), D-mannitol (or delayed), D-glucitol (or delayed), methyl $\alpha$-D-glucoside, salicin (or weak) and inositol are assimilated. L-Sorbose, lactose, inulin, methanol, ethanol, glycerol, erythritol, ribitol (or delayed and weak), DL-lactic acid, succinic acid, citric acid and hexadecane are not assimilated. Ammonium sulfate and L-lysine are assimilated. Potassium nitrate, sodium nitrite, ethylamine hydrochloride and cadaverine dihydrochloride are not assimilated. Maximum growth temperature is $30{ }^{\circ} \mathrm{C}$. Growth in vitamin-free medium is positive (weak). Starch-like substances are not produced. Urease activity is positive. Diazonium Blue $\mathrm{B}$ reaction is positive. The major ubiquinone is $\mathrm{Q}-10$.
The type strain, SY-3.23 $3^{\mathrm{T}}$, was isolated from a wilting leaf of an unidentified plant collected in Sanya, Hainan Province, south China, in December 2006. This strain has been deposited in the China General Microbiological Culture Collection Center (CGMCC), Academia Sinica, Beijing, China, as AS $2.3623^{\mathrm{T}}\left(=\mathrm{CBS} 11408^{\mathrm{T}}\right)$. The GenBank/EMBL/DDBJ accession number for the sequence of the 18S rRNA gene, ITS region and 26S rRNA gene D1/ D2 domain of the type strain is GQ438831.

\section{Latin diagnosis of Mingxiaea hainanensis Q.-M. Wang, F.-Y. Bai, T. Boekhout \& Nakase sp. nov.}

In YM (Difco) liquido post dies 7 ad $17{ }^{\circ} \mathrm{C}$, cellulae vegetativae ellipoideae, ovoideae vel ampulliformes, 2.7$5.5 \times 3.7-7.5 \mu \mathrm{m}$. Annulus et sedimentum formantur. In agaro $\mathrm{YM}$ post unum mensem ad $17^{\circ} \mathrm{C}$, cultura flavae aut brunneo-glauca, non nitida, glabra, butyracea, margine glabra. Mycelium formantur. Ballistoconidia napiformia aut ellipsoideae, $3.0-5.5 \times 5.0-8.0 \mu \mathrm{m}$. Fermentatio nulla. Glucosum, galactosum, saccharosum, maltosum, cellobiosum, trehalosum, melibiosum, raffinosum, melezitosum, amylum solubile, D-xylosum, L-arabinosum, D-arabinosum, D-ribosum, L-rhamnosum, galactitolum (vel lente), D-mannitolum (vel lente), glucitolum (variable), methyl $\alpha$-D-glucosidum (lente et exigue), salicinum (exigue) et inositolum assimilantur 
Table 2. Physiological and biochemical characteristics that differentiate the novel and described species of the genus Mingxiaea gen. nov.

Species: 1, M. sanyaensis sp. nov. (3 strains); 2, M. hainanensis sp. nov. (2 strains); 3, M. foliicola sp. nov. (10 strains); 4, M. wuzhishanensis sp. nov. WZS-29.8 ${ }^{\mathrm{T}}$; 5, M. variabilis (data from Boekhout \& Nakase, 1998); 6, M. pseudovariabilis (Bai et al., 2003); 7, M. begoniae (Nakase et al., 2004); 8, M. siamensis (Fungsin et al., 2003); 9, M. panici (Fungsin et al., 2003); 10, M. setariae (Nakase et al., 2004); 11, B. oberjochense (Sampaio et al., 2002). All species were positive for assimilation of soluble starch. +, positive; -, negative; L, latent; $\mathrm{W}$, weakly positive; LW, latent and weakly positive; $\mathrm{V}$, variable.

\begin{tabular}{|c|c|c|c|c|c|c|c|c|c|c|c|}
\hline Characteristics & 1 & 2 & 3 & 4 & 5 & 6 & 7 & 8 & 9 & 10 & 11 \\
\hline \multicolumn{12}{|l|}{ Assimilation of: } \\
\hline D-Xylose & + & + & + & + & + & + & + & + & + & + & + \\
\hline L-Arabinose & + & + & + & LW & + & + & + & + & + & + & + \\
\hline D-Arabinose & + & + & + & LW & + & + & $\mathrm{L}$ & + & + & + & + \\
\hline D-Ribose & $\mathrm{L},+$ & + &,$+ \mathrm{w}$ & - & + & $\mathrm{L}$ & LW & + & + & $\mathrm{L}$ & $\mathrm{L}$ \\
\hline L-Rhamnose & + & + & + & - & + & + & + & + & + & + & + \\
\hline D-Glucosamine & LW & - &,$+ \mathrm{w}$ & - & + & + & + & LW & W & $\mathrm{W}$ & $\mathrm{L}$ \\
\hline Ribitol &,$- \mathrm{LW}$ &,- LW &,$+ \mathrm{w}$ & - & $\mathrm{V}$ & - & - &,$- \mathrm{LW}$ &,$- \mathrm{LW}$ & $\mathrm{V}$ & $\mathrm{L}$ \\
\hline Galactitol & $\mathrm{LW},+$ &,$+ \mathrm{L}$ & + & LW & + & + & $\mathrm{L}$ & + & + & + & + \\
\hline D-Mannitol & $\mathrm{L},+$ & $\mathrm{L},+$ & + & $\mathrm{L}$ & + & LW & $\mathrm{v}$ & + & + & + & $\mathrm{L}$ \\
\hline D-Glucitol & $\mathrm{L},+$ & $\mathrm{V}$ &,$- \mathrm{LW}$ & - & + & + & L, LW &,$- \mathrm{LW}$ & $\mathrm{V}$ & L, LW & + \\
\hline Methyl $\alpha$-D-glucoside & + & LW &,$+ \mathrm{w}$ & $\mathrm{L}$ & + & - & + & + & + & $\mathrm{L}, \mathrm{LW}$ & + \\
\hline Inositol & + & + & + & - & + & $\mathrm{L}$ & - & + & + & - & + \\
\hline Nitrite & - & - & - &,$- \mathrm{LW}$ & - & - & + & + & + & - & - \\
\hline Ethylamine & - & - & - & - & $\mathrm{V}$ & - & - & + & + & - & - \\
\hline L-Lysine & + & + & + & - & + & + & + & + & + & + & + \\
\hline Cadaverine & - & - & - & - & - & - & LW & + & + & - & - \\
\hline Growth in vitamin-free medium & $\mathrm{w}$ & - & + & - & - & $\mathrm{w}$ & - & - & - & - & - \\
\hline Starch formation & - & - & - & - & + & + & + & $\mathrm{w}$ & $\mathrm{W}$ & - & + \\
\hline
\end{tabular}

at non L-sorbosum, lactosum, inulin, D-glucosaminum, methanolum, ethanolum, glycerolum, erythritolum, ribitolum (vel lente et exigue), acidum DL-lacticum, acidum succinicum, acidum citricum nec hexadecanum. Ammonium sulfatum et L-lysinum assimilantur at non kalium nitricum, natrum nitrosum, ethylaminum et cadaverinum. Vitaminae externae ad crescentiam necessaria sunt. Maxima temperatura crescentiae: $28-30{ }^{\circ} \mathrm{C}$. Materia amyloidea iodophila non formantur. Urea finditur. Diazonium caeruleum $B$ positivum. Ubiquinonum majus: Q-10. Typus: WZS-8.13 ${ }^{\mathrm{T}}$, ex folio Panicum brevifolium L., depositus in collectione China General Microbiological Culture Collection Center, Academia Sinica (AS $2.4161^{\mathrm{T}}$ ).

\section{Description of Mingxiaea hainanensis Q.-M. Wang, F.-Y. Bai, T. Boekhout \& Nakase sp. nov.}

Mingxiaea hainanensis (hai.nan.en'sis. N.L. fem. adj. hainanensis pertaining to Hainan Province, China, the geographical origin of the type strain of this species).

In YM broth, after 7 days at $17{ }^{\circ} \mathrm{C}$, cells are ellipsoidal, ovoid or bottle-shaped $(2.7-5.5 \times 3.7-7.5 \mu \mathrm{m})$ (Fig. $3 \mathrm{c}$ ). Sediment is formed. On YM agar, after 1 month at $17{ }^{\circ} \mathrm{C}$, the streak culture is yellow to brownish-grey, butyrous, dull and smooth. The margin is entire. In Dalmau plate culture on corn meal agar, pseudohyphae and hyphae are not formed. Ballistoconidia are produced on corn meal agar and are napiform or ellipsoidal (3.0-5.5 $\times 5.0-8.0 \mu \mathrm{m})$ (Fig. 3d). Fermentation of glucose is negative. Glucose, galactose, sucrose, maltose, cellobiose, trehalose, melibiose, raffinose, melezitose, soluble starch, D-xylose, L-arabinose, D-arabinose, D-ribose, L-rhamnose, galactitol (or delayed), D-mannitol (or delayed), D-glucitol (variable), methyl $\alpha$-Dglucoside (delayed and weak), salicin (weak) and inositol are assimilated. L-Sorbose, lactose, inulin, D-glucosamine, methanol, ethanol, glycerol, erythritol, ribitol (or delayed and weak), DL-lactic acid, succinic acid, citric acid and hexadecane are not assimilated. Ammonium sulfate and L-lysine are assimilated. Potassium nitrate, sodium nitrite, ethylamine hydrochloride and cadaverine dihydrochloride are not assimilated. Maximum growth temperature is 28$30{ }^{\circ} \mathrm{C}$. Growth in vitamin-free medium is negative. Starchlike substances are not produced. Urease activity is positive. Diazonium Blue $\mathrm{B}$ reaction is positive. The major ubiquinone is Q-10.

The type strain, WZS-8.13 ${ }^{\mathrm{T}}$, was isolated from a wilting leaf of Panicum brevifolium L. collected in Wuzhi Mountain, Hainan Province, south China, in December 2006. This strain has been deposited in the CGMCC as AS $2.4161^{\mathrm{T}}$ (=CBS $\left.11409^{\mathrm{T}}\right)$. The GenBank/EMBL/DDBJ accession number for the sequence of the $18 \mathrm{~S}$ rRNA gene, ITS region and 26S rRNA gene D1/D2 domain of the type strain is GQ438828. 

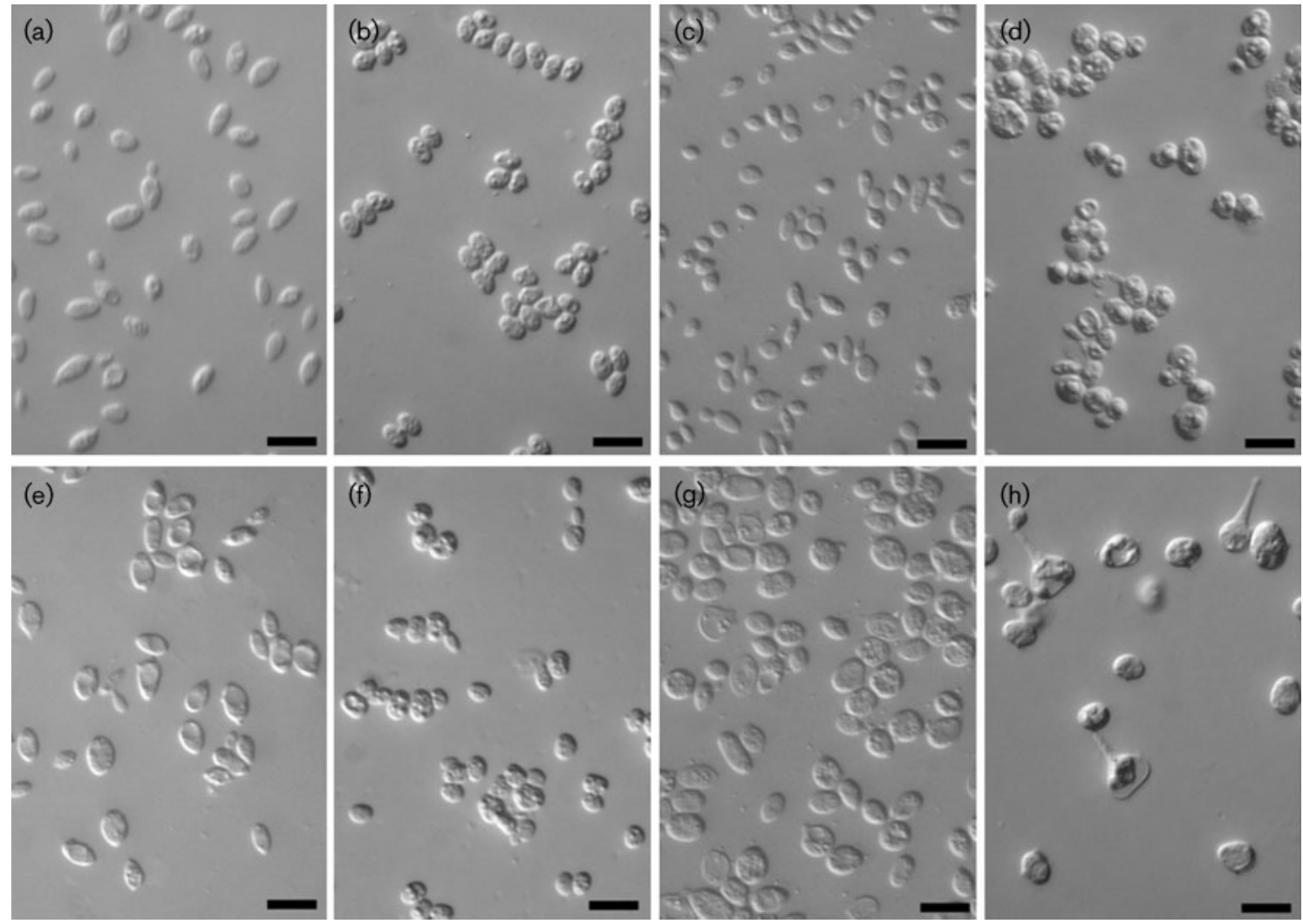

Fig. 3. Vegetative cells $(a, c, e, g)$ grown in $Y M$ broth for 7 days at $17{ }^{\circ} \mathrm{C}$ and ballistoconidia $(b, d, f, h)$ produced on corn meal agar after 7 days at $17{ }^{\circ} \mathrm{C}$ of novel species of the genus Mingxiaea gen. nov. (a, b) Mingxiaea sanyaensis sp. nov. SY-3.23 ${ }^{\top}$; (c, d) Mingxiaea hainanensis sp. nov. WZS-8.13 $3^{\top}$; (e, f) Mingxiaea foliicola sp. nov. WZS-8.14 ${ }^{\top}$; and (g, h) Mingxiaea wuzhishanensis sp. nov. WZS-29.8 ${ }^{\top}$. Bars, $10 \mu \mathrm{m}$.

\section{Latin diagnosis of Mingxiaea foliicola Q.-M. Wang, F.-Y. Bai, T. Boekhout \& Nakase sp. nov.}

In YM (Difco) liquido post dies 7 ad $17^{\circ} \mathrm{C}$, cellulae vegetativae ellipsoideae, ovoideae aut longi-ovoideae, 3.7$5.0 \times 5.0-7.5 \mu \mathrm{m}$. Annulus et sedimentum formantur. In agaro $\mathrm{YM}$ post unum mensem ad $17{ }^{\circ} \mathrm{C}$, cultura brunneoflavae, non nitida, glabra, butyracea, margine glabra. Mycelium non formantur. Ballistoconidia ellipsoideae, 3.0-7.5 × 7.5-10.0 $\mu \mathrm{m}$. Fermentatio nulla. Glucosum, galactosum, saccharosum, maltosum, cellobiosum, trehalosum, melibiosum, raffinosum, melezitosum, amylum solubile, D-xylosum, L-arabinosum, D-arabinosum, D-ribosum (vel exigue), L-rhamnosum, D-glucosaminum (vel exigue), ribitolum (vel exigue), galactitolum, D-mannitolum, methyl $\alpha$-Dglucosidum (vel exigue), salicinum et inositolum assimilantur at non L-sorbosum, lactosum, inulin, methanolum, ethanolum, glycerolum, erythritolum, glucitolum (vel lente et exigue), acidum DL-lacticum, acidum succinicum, acidum citricum nec hexadecanum. Ammonium sulfatum et L-lysinum assimilantur at non kalium nitricum, natrum nitrosum, ethylaminum et cadaverinum. Ad crescentiam vitaminum non necessarium est. Maxima temperatura crescentiae: $28-30{ }^{\circ} \mathrm{C}$. Materia amyloidea iodophila non formantur. Urea finditur. Diazonium caeruleum B positivum. Ubiquinonum majus: Q-10. Typus: WZS-8.14 ${ }^{\mathrm{T}}$, ex folio Panicum brevifolium L., depositus in collectione China General Microbiological Culture Collection Center, Academia Sinica $\left(\right.$ AS $\left.2.3518^{\mathrm{T}}\right)$.

\section{Description of Mingxiaea foliicola Q.-M. Wang, F.-Y. Bai, T. Boekhout \& Nakase sp. nov.}

Mingxiaea foliicola (fol.i.i' co.la. foliicola L. n. folium, a leaf; L. suff. - cola (from L. n. incola), inhabitant, dweller; N.L. n. foliicola, living in leaves, referring to the source of the type strain).

In YM broth, after 7 days at $17{ }^{\circ} \mathrm{C}$, cells are ellipsoidal or ovoid to long-ovoid $(3.7-5.0 \times 5.0-7.5 \mu \mathrm{m})$ (Fig. 3e). Sediment is formed. On YM agar, after 1 month at $17{ }^{\circ} \mathrm{C}$, the streak culture is brownish-yellow, butyrous, dull and smooth. The margin is entire. In Dalmau plate culture on cornmeal agar, pseudohyphae and hyphae are not formed. Ballistoconidia are produced on corn meal agar and are ellipsoidal $(3.0-7.5 \times 7.5-10.0 \mu \mathrm{m})$ (Fig. 3f). Fermentation of glucose is negative. Glucose, galactose, sucrose, maltose, cellobiose, trehalose, melibiose, raffinose, 
melezitose, soluble starch, D-xylose, L-arabinose, D-arabinose, D-ribose (or weak), L-rhamnose, D-glucosamine (or weak), ribitol (or weak), galactitol, D-mannitol, methyl $\alpha$-D-glucoside (or weak), salicin and inositol are assimilated. L-Sorbose, lactose, inulin, methanol, ethanol, glycerol, erythritol, D-glucitol (or delayed and weak), DL-lactic acid, succinic acid, citric acid and hexadecane are not assimilated. Ammonium sulfate and L-lysine are assimilated. Potassium nitrate, sodium nitrite, ethylamine hydrochloride and cadaverine dihydrochloride are not assimilated. Maximum growth temperature is $28-30{ }^{\circ} \mathrm{C}$. Growth in vitamin-free medium is positive. Starch-like substances are not produced. Urease activity is positive. Diazonium Blue B reaction is positive. The major ubiquinone is Q-10.

The type strain, WZS- $8.14^{\mathrm{T}}$, was isolated from a wilting leaf of Panicum brevifolium L. collected in Wuzhi Mountain, Hainan Province, south China, in December 2006. This strain has been deposited in the CGMCC as AS $2.3518^{\mathrm{T}}$ $\left(=\mathrm{CBS} 11407^{\mathrm{T}}\right)$. The GenBank/EMBL/DDBJ accession number for the sequence of the 18S rRNA gene, ITS region and 26S rRNA gene D1/D2 domain of the type strain is GQ438834.

\section{Latin diagnosis of Mingxiaea wuzhishanensis Q.-M. Wang, F.-Y. Bai, T. Boekhout \& Nakase sp. nov.}

In YM (Difco) liquido post dies 7 ad $17{ }^{\circ} \mathrm{C}$, cellulae vegetativae globosae, ellipsoideae vel ovoideae, 3.0-7.5 ×5.5-9.9 $\mu \mathrm{m}$. Annulus et sedimentum formantur. In agaro $\mathrm{YM}$ post unum mensem ad $17{ }^{\circ} \mathrm{C}$, cultura cremea aut aurantiaca-flavae, non nitida, glabra, butyracea, margine glabra. Mycelium et peudomycelium non formantur. Ballistoconidia ellipsoideae, 3.0-7.5 $\times 6.2-8.7 \mu \mathrm{m}$. Fermentatio nulla. Glucosum, galactosum, saccharosum, maltosum, cellobiosum (lente et exigue), trehalosum, melibiosum, raffinosum, melezitosum, amylum solubile, D-xylosum, L-arabinosum (lente et exigue), D-arabinosum (lente et exigue), galactitolum (lente et exigue), $\mathrm{D}$-mannitolum (lente), methyl $\alpha$-D-glucosidum (lente), et salicinum (lente et exigue) assimilantur at non L-sorbosum, lactosum, inulin, D-ribosum, L-rhamnosum, D-glucosaminum, methanolum, ethanolum, glycerolum, erythritolum, ribitolum, glucitolum, acidum DL-lacticum, acidum succinicum, acidum citricum, inositolum nec hexadecanum. Ammonium sulfatum assimilantur at non kalium nitricum, natrum nitrosum, L-lysinum, ethylaminum et cadaverinum. Vitaminae externae ad crescentiam necessaria sunt. Maxima temperatura crescentiae: $28{ }^{\circ} \mathrm{C}$. Materia amyloidea iodophila non formantur. Urea finditur. Diazonium caeruleum B positivum. Ubiquinonum majus: Q-10. Typus: WZS-29.8 ${ }^{\mathrm{T}}$, ex folio plantae incognitae, depositus in collectione China General Microbiological Culture Collection Center, Academia Sinica (AS 2.4163 ${ }^{\mathrm{T}}$ ).

\section{Description of Mingxiaea wuzhishanensis Q.-M. Wang, F.-Y. Bai, T. Boekhout \& Nakase sp. nov.}

Mingxiaea wuzhishanensis (wu.zhi.shan.en'sis. N.L. fem. adj. wuzhishanensis pertaining to Wuzhi Mountain, Hainan
Province, China, referring to the geographical origin of the type strain of this species).

In YM broth, after 7 days at $17{ }^{\circ} \mathrm{C}$, cells are globose, ellipsoidal, or ovoid $(3.0-7.5 \times 5.5-9.9 \mu \mathrm{m})$ (Fig. 3g). Sediment is formed. On YM agar, after 1 month at $17{ }^{\circ} \mathrm{C}$, the streak culture is dark-cream to orange-yellow, butyrous, dull and smooth. The margin is entire. In Dalmau plate culture on corn meal agar, mycelium and pseudohyphae are not formed. Ballistoconidia are produced on corn meal agar and are ellipsoidal (3.0-7.5 $\times 6.2-$ $8.7 \mu \mathrm{m}$ ) (Fig. 3h). Fermentation of glucose is negative. Glucose, galactose, sucrose, maltose, cellobiose (delayed and weak), trehalose, melibiose, raffinose, melezitose, soluble starch, D-xylose, L-arabinose (delayed and weak), $\mathrm{D}$-arabinose (delayed and weak), galactitol (delayed and weak), D-mannitol (delayed), methyl $\alpha$-D-glucoside (delayed) and salicin (delayed and weak) are assimilated. L-Sorbose, lactose, inulin, D-ribose, L-rhamnose, D-glucosamine, methanol, ethanol, glycerol, erythritol, ribitol, D-glucitol, DL-lactic acid, succinic acid, citric acid, inositol and hexadecane are not assimilated. Ammonium sulfate is assimilated. Potassium nitrate, sodium nitrite, L-lysine, ethylamine hydrochloride, and cadaverine dihydrochloride are not assimilated. Maximum growth temperature is $28{ }^{\circ} \mathrm{C}$. Growth in vitamin-free medium is negative. Starchlike substances are not produced. Urease activity is positive. Diazonium Blue B reaction is positive. The major ubiquinone is Q-10.

The type strain, WZS $-29.8^{\mathrm{T}}$, was isolated from a wilting leaf of an unidentified plant collected in Wuzhi Mountain, Hainan Province, south China, in December 2006. This strain has been deposited in the as AS $2.4163^{\mathrm{T}}$ (=CBS $11411^{\mathrm{T}}$ ). The GenBank/EMBL/DDBJ accession number for the sequence of the 18S rRNA gene, ITS region and $26 \mathrm{~S}$ rRNA gene D1/D2 domain of the type strain is GQ438830.

\section{ACKNOWLEDGEMENTS}

This study was supported by the National Natural Science Foundation of China (NSFC) (grant nos 30825002 and 30700001).

\section{REFERENCES}

Bai, F.-Y., Takashima, M. \& Nakase, T. (2001). Phylogenetic analysis of strains originally assigned to Bullera variabilis: descriptions of Bullera pseudohuiaensis sp. nov., Bullera komagatae sp. nov. and Bullera pseudoschimicola sp. nov. Int J Syst Evol Microbiol 51, 21772187.

Bai, F.-Y., Zhao, J.-H., Takashima, M., Jia, J.-H., Boekhout, T. \& Nakase, T. (2002). Reclassification of the Sporobolomyces roseus and Sporidiobolus pararoseus complexes, with the description of Sporobolomyces phaffii sp. nov. Int J Syst Evol Microbiol 52, 23092314.

Bai, F.-Y., Takashima, M., Zhao, J.-H., Jia, J.-H. \& Nakase, T. (2003). Bullera anomala sp. nov. and Bullera pseudovariabilis sp. nov., two new ballistoconidium-forming yeast species from Yunnan, China. Antonie van Leeuwenhoek 83, 257-263. 
Boekhout, T., Fonseca, A. \& Batenburg-van der Vegte, W. H. (1991). Bulleromyces genus novum (Tremellales), a teleomorph for Bullera $a l b a$, and the occurrence of mating in Bullera variabilis. Antonie van Leeuwenhoek 59, 81-93.

Boekhout, T. \& Nakase, T. (1998). Bullera Derx. In The Yeasts, a Taxonomic Study, 4th edn, pp. 731-741. Edited by C. P. Kurtzman \& J. W. Fell. Amsterdam: Elsevier.

Fell, J. W., Boekhout, T., Fonseca, A., Scorzetti, G. \& StatzellTallman, A. (2000). Biodiversity and systematics of basidiomycetous yeasts as determined by large-subunit rDNA D1/D2 domain sequence analysis. Int J Syst Evol Microbiol 50, 1351-1371.

Felsenstein, J. (1985). Confidence limits on phylogenies: an approach using the bootstrap. Evolution 39, 783-791.

Fungsin, B., Takashima, M., Bai, F.-Y., Artjariyasripong, S. \& Nakase, T. (2003). Bullera panici sp. nov. and Bullera siamensis sp. nov., two new yeasts in the Bullera variabilis cluster isolated in Thailand. Microbiol Cult Collect 19, 23-32.

Fungsin, B., Takashima, M., Sugita, T., Artjariyasripong, S., Potacharoen, W., Tanticharoen, M. \& Nakase, T. (2006). Bullera koratensis sp. nov. and Bullera lagerstroemiae sp. nov., two new ballistoconidium-forming yeast species in the Trichosporonales clade isolated from plant leaves in Thailand. J Gen Appl Microbiol 52, 73-81.

Kimura, M. (1980). A simple method for estimating evolutionary rates of base substitutions through comparative studies of nucleotide sequences. J Mol Evol 16, 111-120.

Nakase, T. \& Suzuki, M. (1987). Bullera variabilis, a new species of yeast with uniquely-shaped ballistospores isolated from various plant materials. J Gen Appl Microbiol 33, 343-354.

Nakase, T. \& Takashima, M. (1993). A simple procedure for the high frequency isolation of new taxa of ballistosporous yeasts living on the surfaces of plants. RIKEN Review 3, 33-34.

Nakase, T., Tsuzuki, S. \& Takashima, M. (2002). Bullera taiwanensis sp. nov. and Bullera formosensis sp. nov., two new ballistoconidiumforming yeasts isolated from plant leaves in Taiwan. J Gen Appl Microbiol 48, 345-355.

Nakase, T., Tsuzuki, S., Lee, F. L., Jindamorakot, S., Jan-ngam, H., Potacharoen, W., Tanticharoen, M., Kudo, T. \& Takashima, M. (2004). Bullera begoniae sp. nov. and Bullera setariae sp. nov., two new species of ballistoconidium-forming yeasts in the Bullera variabilis (Bulleribasidium) cluster isolated from plants in Taiwan. Mycoscience 45, 287-294.

Saitou, N. \& Nei, M. (1987). The neighbor-joining method: a new method for reconstructing phylogenetic trees. Mol Biol Evol 4, 406-425.

Sampaio, J. P., Weiß, M., Gadanho, M. \& Bauer, R. (2002). New taxa in the Tremellales: Bulleribasidium oberjochense gen. et sp. nov., Papiliotrema bandonii gen. et sp. nov. and Fibulobasidium murrhardtense sp. nov. Mycologia 94, 873-887.

Scorzetti, G., Fell, J. W., Fonseca, A. \& Statzell-Tallman, A. (2002). Systematics of basidiomycetous yeasts: a comparison of large subunit D1/D2 and internal transcribed spacer rDNA regions. FEMS Yeast Res 2, 495-517.

Takashima, M. \& Nakase, T. (1999). Molecular phylogeny of the genus Cryptococcus and related species based on the sequences of $18 \mathrm{~S}$ rDNA and internal transcribed spacer regions. Microbiol Cult Collect $15,35-47$.

Tamura, K., Dudley, J., Nei, M. \& Kumar, S. (2007). MEGA4: molecular evolutionary genetics analysis (MEGA) software version 4.0. Mol Biol Evol 24, 1596-1599.

Thompson, J. D., Gibson, T. J., Plewniak, F., Jeanmougin, F. \& Higgins, D. G. (1997). The CLUSTAL_X windows interface: flexible strategies for multiple sequence alignment aided by quality analysis tools. Nucleic Acids Res 25, 4876-4882.

Wang, Q.-M. \& Bai, F.-Y. (2008). Molecular phylogeny of basidiomycetous yeasts in the Cryptococcus luteolus lineage (Tremellales) based on nuclear rRNA and mitochondrial cytochrome $b$ gene sequence analyses: proposal of Derxomyces gen. nov. and Hannaella gen. nov., and description of eight novel Derxomyces species. FEMS Yeast Res $\mathbf{8}$, 799-814.

Wang, Q.-M., Bai, F.-Y., Zhao, J.-H. \& Jia, J.-H. (2003). Dioszegia changbaiensis sp. nov., a basidiomycetous yeast species isolated from northeast China. J Gen Appl Microbiol 49, 295-299.

Yamada, Y. \& Kondo, K. (1973). Coenzyme Q system in the classification of the yeast genera Rhodotorula and Cryptococcus and the yeast-like genera Sporobolomyces and Rhodosporidium. J Gen Appl Microbiol 19, 59-77.

Yarrow, D. (1998). Methods for the isolation, maintenance and identification of yeasts. In The Yeasts, a Taxonomic Study, 4th edn, pp. 77-100. Edited by C. P. Kurtzman \& J. W. Fell. Amsterdam: Elsevier. 